\title{
Celas e Elas: Desmontando cenas e construindo lugares de fala e escuta no teatro feminista
}

\author{
Daiane Dordete Steckert Jacobs \\ Universidade do Estado de Santa Catarina/ UDESC, Brasil \\ E-mail: ddordete@gmail.com
}

\section{Resumo}

Este artigo imbrica relatos e reflexões sobre o processo de criação da (des)montagem teatral e perfopalestra celas e elas, experiência teatral que aborda a opressão de gênero em prisões metafóricas e reais de mulheres, como um exercício de lugares de fala e de escuta no teatro feminista.

\section{Palavras-chave}

Celas e Elas. Lugar de Fala e Lugar de Escuta. Desmontagem Teatral. Perfopalestra.

Teatro Feminista.
This paper imbues reports and reflections on the process of creating the theatrical (de)montage and performance lecture celas e elas, a theatrical experience that addresses gender oppression in metaphorical and real women's prisons, as an exercise of standpoints of speech and listening in feminist theater.

\section{Keywords}

Celas e Elas. Standpoint of Speech and Standpoint of Listening. Theatrical Desmontage, Performance Lecture. Feminist Theatre. 


\section{Um lance de olhar sobre o caleidoscópio}

Há 11 anos venho trabalhando em parceria com a Vai! Coletivo ${ }^{1}$, de Joinville-SC, na pesquisa sobre muIheres em situação de cárcere e opressões de gênero. Em 2010 iniciamos um projeto de montagem teatral com este foco, motivadas pela necessidade de discutir através da arte as violências às quais as mulheres são submetidas diuturnamente, desde o contexto do sistema prisional brasileiro, que amplifica estas violências em muitos pontos, até a reflexão sobre os machismos e misoginias que engendram o cotidiano das mulheres na vida profissional, social, familiar e afetiva.

Nestes 10 anos montamos e desmontamos uma peça de teatro, realizamos diversas rodas de conversa após as apresentações, ministramos aulas de teatro para mulheres em situação de cárcere e montamos uma exposição ${ }^{2}$ para registrar um pouco dos processos mais recentes do projeto "celas e elas: teatro com mulheres em privação de liberdade"3.

Neste texto, procuro localizar minhas reflexões nas motivações e referências iniciais da montagem da peça celas, bem como na transformação deste trabalho em uma desmontagem teatral e perfopalestra intitulada celas e elas. Meu intuito é também discorrer sobre lugares de fala e de escuta nestes percursos, percebendo o processo criativo como um reflexo das questões éticas, estéticas e políticas das artistas envolvidas nesta experiência de teatro feminista, a partir da minha visão de diretora e dramaturga.

1 A Vai! Coletivo era denominada, até fim de 2020, como Cia.VAi!- núcleo de pesquisa em artes cênicas. Foi fundada em 26 de outubro de 2009. Integram a companhia: Samira Sinara, Jackson Luis, Marlon Zé e Raphael Vianna. Maiores informações: https://www.facebook.com/vaicoletivo

2 Exposição Para Além das Celas. Fotos: Jéssica Michels. Curadoria: Daiane Dordete, Jéssica Michels e Samira Sinara. Patrocínio: Sistema Municipal de Apoio à Cultura - Joinville/SC.

3 Proponente: Samira Sinara Souza. Patrocínio: Sistema Municipal de Apoio à Cultura - Joinville/SC.

\section{No início era(m) celas}

Em 2011 estreou em Joinville-SC a peça celas ${ }^{4}$, trabalho que emergiu de um processo criativo que durou mais de um ano e teve a participação de uma grande equipe ${ }^{5}$. Eu trabalhei na direção e na dramaturgia da peça, que partiu de relatos de mulheres em situação de cárcere e de mulheres libertas da ala feminina ${ }^{6}$ do Presídio Regional de Joinville (PRJ). Ambas as pesquisas ${ }^{7}$ haviam sido realizadas por Camila Diane Silva ${ }^{8}$ no programa de iniciação científica do-

4 Patrocínio: SIMDEC - Sistema Municipal de Desenvolvimento pela Cultura, Fundação Cultural de Joinville e Prefeitura Municipal de Joinville.

5 Ficha técnica da primeira versão da peça (2011):

Direção, dramaturgia, vídeos, cenário, figurino e caracterização: Daiane Dordete

Assistência de direção e operação de mídias: Alex Maciel Atuação: Samira Sinara

Pesquisadora: Camila Diane Silva

Trilha sonora original: Cleiton Jacobs

lluminação e operação de luz: Flávio Andrade

Registro audiovisual: Fabrício e Fábio Porto

Design gráfico: Núcleo de Comunicação - CEART-UDESC

Cenotécnica: Cleiton Jacobs e Daiane Dordete

Costura: Loja Dida Modas

Produção e Realização: CiA.VAi!- núcleo de pesquisa em artes cênicas

Patrocínio: SIMDEC - Sistema Municipal de Desenvolvimento pela Cultura, Fundação Cultural de Joinville e Prefeitura Municipal de Joinville.

Apoio Cultural: AJOTE, UDESC e UNIVILLE.

6 O Presídio Regional de Joinville (PRJ) possuiu até fim de 2020 uma pequena ala, com duas galerias, para as mulheres detentas, pois o Presídio Feminino da cidade, embora já construído, ainda não está em funcionamento devido à falta de servidores. A ala era insuficiente para a quantidade de detentas, algumas já condenadas e outras aguardando o julgamento, e recorrentemente estava superlotada. No fim de 2020 a ala foi desativada e as detentas foram realocadas para outros presídios de Santa Catarina.

7 "Crimes, celas e elas: memórias de mulheres sobre a condição de cárcere" e "Narrativas de Mulheres Egressas do sistema carcerário na cidade de Joinville" foram as pesquisas desenvolvidas por Camila Diane Silva, realizadas durante os anos de 2008 e 2009.

8 Possui Graduação em História pela Universidade da Região de Joinville (UNIVILLE). Mestrado em História pelo Programa de Pós Graduação em História Cultural da Universidade Federal de Santa Catarina (UFSC). Atualmente é doutoranda em História pelo Programa de Pós Graduação em História Global da Universidade Federal de Santa Catarina (UFSC). 
curso de História da UNIVILLE ${ }^{9}$. A partir da transcrição e das gravações ${ }^{10}$ das entrevistas, Samira Sinara ${ }^{11}$, Alex Maciel ${ }^{12}$ e eu fomos elencando o que percebíamos como motivações, sentimentos e paradigmas recorrentes enfrentados por estas mulheres tanto nos tropeços e desvios legais quanto no cárcere e na reinserção social. Motivadas pela identificação destes elementos, fomos criando pequenas performances, procurando sempre levar em conta nossos lugares, corpos e vozes como mulheres livres, brancas, de classe média, heterossexuais, ou seja, nossos lugares de fala ${ }^{13}$. Quem somos nós? Como estas questões nos afetam? Que memórias eu tenho disso? O que eu sinto quanto eu penso nisso? O que meu corpo e minha voz lembram? Com questões como estas fomos construindo a dramaturgia da cena, em um diálogo e processo contínuo entre as ações, a dramaturgia da atriz, a dramaturgia textual, a luz, a música, o espaço, a cenografia e a encenação. Naquele momento, optamos por não representar estas mulheres em cena, nem o ambiente real da prisão, mas percebemos que fragmentos das histórias delas se ligavam às nossas, e às histórias de muitas mulheres que conhecíamos. Percebemos que eram memórias, de-

9 Universidade da Região de Joinville.

10 O registro em áudio das entrevistas está disponível no Laboratório de História Oral da UNIVILLE.

11 Atriz de celas.

12 Assistente de direção de celas em 2011.

13 No livro O que é lugar de fala? (2017) a filósofa e ativista Djamilla Ribeiro desenvolve o conceito que dá título à obra a partir do pensamento de filósofas como Gayatri Spivak, Patrícia Hill Collins, Grada Kilomba e Linda Alcoff. Lugar de fala define um espaço discursivo social, que carrega consigo as relações históricas de poder, opressão, exploração e privilégio: "Assim, entendemos que todas as pessoas possuem lugar de fala, pois estamos falando de localização social. E a partir disso é possível debater e refletir criticamente sobre os mais variados temas presentes na sociedade. $O$ fundamental é que indivíduos pertencentes ao grupo social privilegiado em termos de locus social consigam enxergar as hierarquias produzidas a partir desse lugar e como esse lugar impacta diretamente na constituição dos lugares de grupos subalternizados." (RIBEIRO, 2017, p. 88). sejos, pesadelos, traumas de opressões e violências de gênero diversas, que emergiram desta pesquisa e se transformaram no solo performático multimídia que estreou em dezembro de 2011. celas ficou em cartaz até meados de 2015 , com seu cenário formado por um andaime de 5 metros de altura, que se transformava em diálogo com as projeções de vídeo em tela, iluminação e trilha sonora. celas procurava ser a metáfora de muitas prisões que circundam e habitam os diversos contextos de vida das mulheres.

Figura 1 - celas: A atriz Samira Sinara em cena de celas. Apresentação realizada no Galpão de Teatro da AJOTE - Associação Joinvilense de Teatro, em agosto de 2012, durante a Mostra Cena 9.

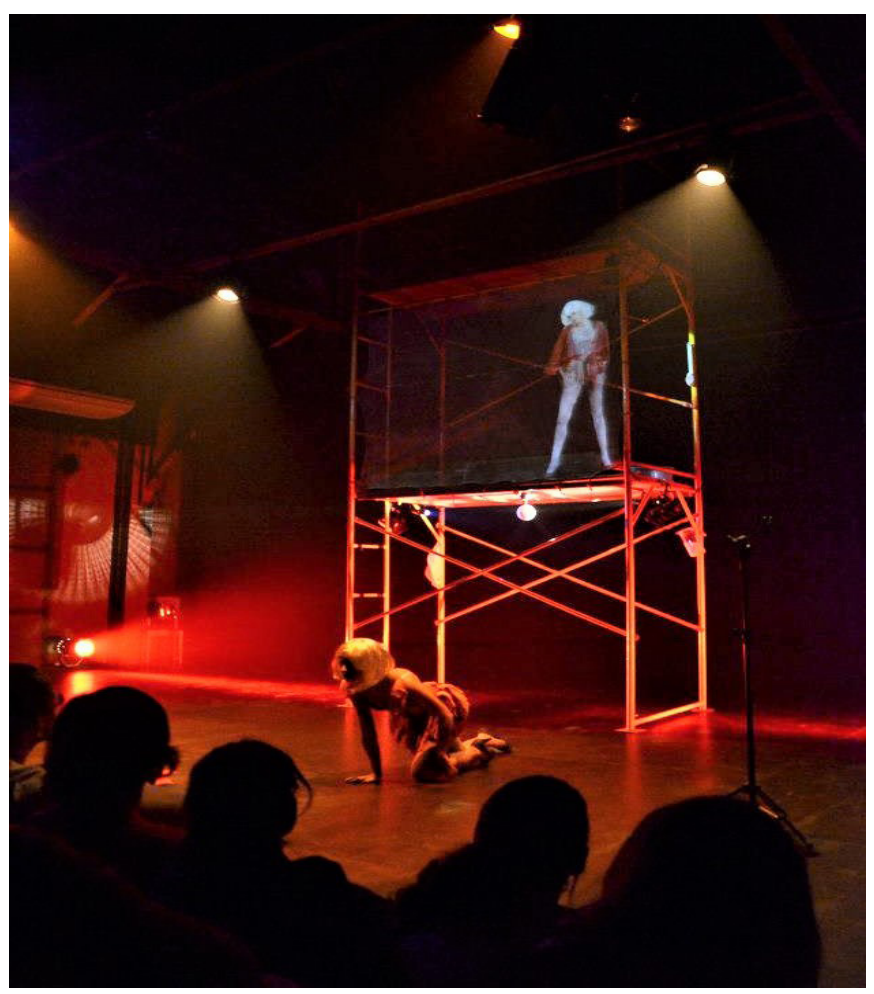

Fonte: Fotografia de Jaqueline Mello e Rosani.

celas foi apresentado ${ }^{14}$ para as detentas do PRJ em março de 2012. Como em toda apresentação da peça, houve uma roda de conversa ao final.

14 A apresentação ocorreu em 08/03/2012, com diversas adaptações devido ao espaço disponível (pátio de sol). $O$ andaime teve a redução de um piso e a iluminação e as projeções não puderam ser realizadas devido à luminosidade do espaço aberto. 
Muitas mulheres relataram ${ }^{15}$ identificação com as cenas sobre maternidade, trabalho, vícios, sexualização do corpo, dentre outras. Mas além de todas estas violências cotidianas, elas conviviam diuturnamente na prisão com o abandono da família, o esquecimento da sociedade, o apagamento da autoimagem e da autoestima, o esfacelamento da humanidade em contextos de precarização da vida e do acesso a produtos de primeira necessidade, como materiais de higiene. O sistema que deveria preparar as pessoas para a ressocialização, pune o corpo na privação de espaço, de relação, de afeto, de autoestima e de saúde.

Eram celas grandes demais que envolviam estas mulheres. Nosso cenário ficou pequeno no final deste percurso.

\section{Encontrando com elas na "cela de aula"}

Quando resolvemos parar com as apresentações de celas $^{16}$, por diversos motivos - como a dificuldade em transportar o pesado cenário e equipamentos, dificuldade em manter uma rotina de ensaios e preparação física para a peça pelo fato de eu e Samira morarmos em cidades diferentes (Florianópolis e Joinville), etc. - , sentimos a necessidade de dar um retorno maior para as mulheres do PRJ. Samira teve então a ideia de escrever um projeto de oficina de teatro na prisão. Neste mesmo projeto propusemos a remontagem da peça celas, pensando em reelaborar a cenografia (para algo mais leve!), rever cenas e atualizar discussões, afinal, muitos anos já haviam passado desde a montagem original.

Com o apoio imprescindível do Centro de Direitos Humanos e da Pastoral Carcerária de Joinville, conseguimos autorização da direção do PRJ para

15 Os relatos das mulheres em situação de cárcere foram coletados oralmente e me repassados por Samira Sinara.

16 A peça continuou com apresentações até 2015, incluindo participação no Festival Catarinense de Teatro e circulação estadual pelo projeto Encena Catarina do SESC-SC, ambos em 2013. submissão do projeto ${ }^{17}$, que foi aprovado no Edital de Apoio à Cultura de Joinville em 2017 para realização em 2018. Por orientação da direção do PRJ, durante todo o ano de 2018 aguardamos a finalização das obras do tão esperado Presídio Feminino, que teria espaços mais adequados para atividades educacionais, e poderia comportar a oficina de teatro. $\mathrm{O}$ Presídio foi construído. Porém, até início de 2019 não havia indicativo de concurso público ou processo seletivo para a contratação de servidores para a unidade poder operar. Decidimos então, juntamente à direção do $P R J$, iniciar as aulas na única sala de aula disponível no PRJ, para não perder o prazo de execução do projeto (que já havia sido prorrogado).

O espaço para as aulas era de uso comum, para homens e mulheres do PRJ. Uma sala pequena, com uma grade separando o espaço de estudantes e professoras. Apenas os homens estavam recebendo aulas do $\mathrm{EJA}^{18}$. As mulheres, apesar de serem em torno de 50 quando iniciamos o projeto, e em torno de 80 quando finalizamos, não tinham aulas. As únicas atividades educativas ou culturais ou de qualquer espécie que elas tiveram durante o ano de 2019 foram as aulas de teatro e as apresentações de nossa peça, a desmontagem celas e elas, após o fim da oficina de teatro. No mais, eram 22 horas por dia dentro das pequenas celas superlotadas, e 02 horas por dia de banho de sol.

As aulas de teatro foram ministradas entre fevereiro e junho de 2019 para duas turmas com

17 Patrocínio: SIMDEC - Sistema de Desenvolvimento pela Cultura, Secretaria de Cultura e Turismo, Prefeitura Municipal de Joinville/SC. Apoio: UDESC, SESC, Casa Iririú.

18 Educação de Jovens e Adultos. O acesso à educação básica é direito de toda pessoa em privação de liberdade, de acordo com o disposto nos seguintes instrumentos legais: Lei de Execução Penal (LEP) - Lei n7.210/1984; Resolução n03/2009 do Conselho Nacional de Política Criminal e Penitenciária do Ministério da Justiça; Resolução CNE/CEB n02, de 19 de maio de 2010 - Dispõe sobre as Diretrizes Nacionais para a oferta de educação para jovens e adultos em situação de privação de liberdade nos estabelecimentos penais; Decreto $n^{\circ} 7.626 / 2011$, que institui o Plano Estratégico de Educação no âmbito do sistema prisional. 
uma média ${ }^{19}$ de 10 alunas cada, que tiveram aulas semanais de 02 horas de duração, totalizando 30 horas de oficina presencial para cada grupo. A oficina abordou uma introdução ao teatro através de jogos teatrais, jogos e exercícios corpóreo-vocais, canto coletivo e jogos sonoro-musicais, além de aulas teóricas introdutórias, com exposição oral e exibição de filme. Na finalização da oficina as duas turmas apresentaram uma pequena colagem de jogos teatrais e músicas trabalhadas durante o semestre para um pequeno público convidado ${ }^{20}$.

Eu e Samira éramos atravessadas semanalmente pelo encontro com estas mulheres. Nos olhares treinados a mirar o chão, nas inseguranças mútuas e nas tentativas de atravessar as grades da "cela de aula", tentávamos descobrir algum tipo de conexão naquele lugar que se transformava a cada aula pelas possibilidades da imaginação, da ludicidade e da arte. Foram muitos os desafios, descobertas e emoções partilhadas neste processo artístico e pedagógico, que pudemos discutir em outro artigo ${ }^{21}$ recém publicado. Mas cabe registrar aqui que a força desse encontro mobilizou novos caminhos para o objeto de reflexão deste texto: a (des)montagem da peça celas em 2019.

\section{Desmontagem e perfopalestra: caminhos para celas e elas}

Paralelamente à realização das oficinas de teatro na prisão, eu e Samira remontamos o espetáculo celas, que havíamos estreado em 2011. Todavia, após sermos atravessadas pelo cotidiano da prisão em nossas aulas semanais em 2019, e pelas histórias e contexto das mais de 30 mulheres que frequentaram o curso de teatro, percebemos que não poderíamos apenas reensaiar a peça, com pequenas alterações.

19 Ao total, 34 alunas passaram pela oficina.

20 Estavam presentes representantes do Presídio Regional de Joinville, Pastoral Carcerária de Joinville, Centro de Direitos Humanos de Joinville, Vara de Execuções Penais de Joinville e UDESC-CEART.

21 Cf.: JACOBS; SOUZA, 2020.
Em nossos ensaios, que inicialmente foram discussões, compartilhamentos de angústias e desejos, e proposições, decidimos procurar mais espaços para as histórias das mulheres em situação de cárcere. Eram histórias pessoais, mas atravessadas por questões políticas que se refletem em legislações injustas, práticas institucionais machistas e falta de suporte social e econômico para se manter uma vida digna. As violências de gênero que se multiplicam neste contexto hostil precisavam ser discutidas com o público.

Para tal, a linguagem da peça precisava ser reinventada também. Propus então à Samira que trabalhássemos com duas diretrizes na linguagem: a desmontagem teatral e a perfopalestra. A desmontagem nos permitiria revisitar a peça já criada, e compartilhar com o público o processo de pesquisa e criação, além de (re)criar algumas cenas. E a perfopalestra nos possibilitaria uma abordagem objetiva e crítica sobre o contexto das mulheres no cárcere.

Mas, como desmontar celas?

Ileana Diéguez Caballero (2018) contextualiza a emergência de novos formatos cênicos com vistas ao compartilhamento de processos criativos na América Latina no fim dos anos 1970, sobretudo em eventos convocados pela EITALC - Escola Internacional de Teatro de América Latina e Cari$b^{22}$. As desmontagens teatrais não confabulam uma estética. Antes disso, compartilham estrategicamente a exposição dos processos criativos, suas motivações éticas, políticas, estéticas, seus percursos e percalços, em uma ação pedagógica e performática. São "(...) um 'desarranjo da composição', uma problematização dos cenários teóricos, técnicos, poéticos, espirituais que foram se tecendo durante a viagem individual e coletiva" (CABALLERO, 2018, p. 15) que desaguou na criação artística.

22 Segundo Caballero, a EITALC foi uma “(...) 'escola' itinerante e virtual, que gerou uma aproximação a processos de investigação mais do que à confirmação de resultados, fora do espírito festivo daquele tempo, propiciando o diálogo entre pesquisadores/teóricos e criadores, gerando outros olhares e outra praxe na pesquisa interessada em se aproximar dos processos, em conhecer estes e questioná-los, não sendo venerados ou negados" (2018, p. 16). 
Assim, as oito cenas do celas original foram desmontadas e reinventadas, transformando-se em sete momentos da desmontagem. O espaço cênico foi reconfigurado, e a frontalidade deu espaço a uma partilha intimista para pequenas salas e espaços alternativos, sem a necessidade de urdimento e equipamentos de luz ou som. A iluminação foi sintetizada na própria cenografia, e a trilha sonora passou a ser reproduzida em uma pequena maleta de som, também cenográfica.

Figura 2 - Celas e Elas - A atriz Samira Sinara em cena de celas e elas. Apresentação realizada no Espaço Cultural Casa Iririú, em Joinville-SC, em julho de 2019.

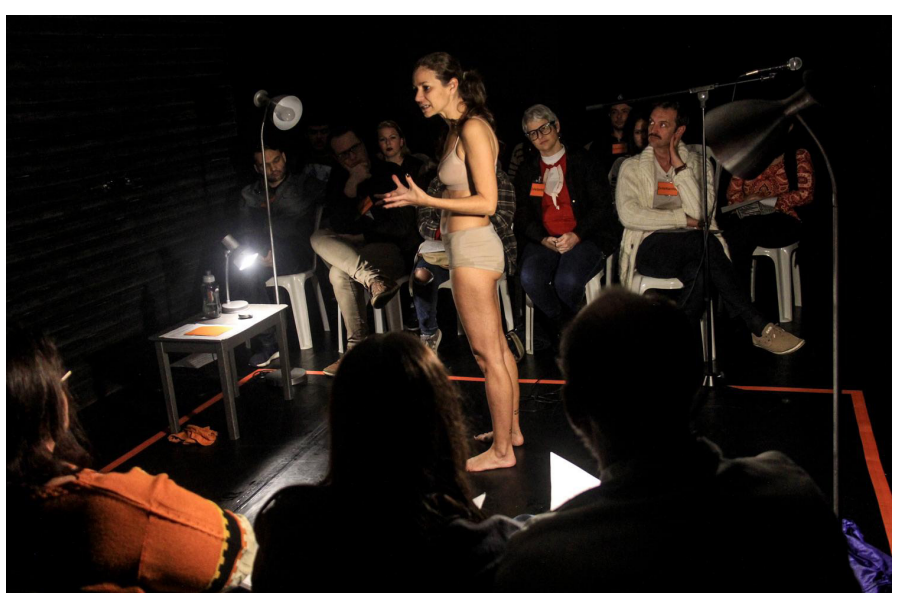

Fonte: Fotografia de Jéssica Michels.

Em um dos ensaios, quando eu e Samira compartilhávamos desejos e angústias sobre o trabalho em processo, comentei com ela sobre uma conversa que tive com minha mãe. Antes de iniciar os ensaios da desmontagem, eu expliquei para minha mãe o projeto e nossa empolgação em dar continuidade à pesquisa e ao trabalho. E convidei-a pra assistir novamente a peça. Ela, muito animada, nos parabenizou, e prometeu ir. Aí eu pedi que ela levasse meu pai também, e ela, meio reticente, disse: "não sei se ele vai querer ir, filha. Da última vez que vocês apresentaram ele disse que não entendeu nada..... Essas palavras me pertubaram. Por que ele havia dito isso?
Na proposta de encenação ${ }^{23}$ da montagem originalde celasapresentávamos a seguinteargumentação:

O espetáculo foi concebido a partir de estudos da performance e da performance art. Pretende-se criar uma cena performativa, na qual a justaposição e constante deslocamento dos signos cênicos geram sentidos instáveis. Tanto atuação (corpo e voz) quanto a cenografia, figurino, iluminação, música, ambiência sonora e texto apontam a cada cena universos diferentes, habitados por uma mesma atriz, que esboça diversas mulheres em suas performances.

A hibridez de linguagem (dança, vídeo, teatro, ritual) se revela no percurso dos 8 quadros do espetáculo, que reorganizam o espaço dividido pela atriz e pelos partícipes a todo momento, procurando estabelecer constantemente novas redes de contaminação nos corpos que compartilham este mesmo tempo-espaço de experiência sinestésica.

A encenação e a dramaturgia partiram de pesquisas sobre mulheres carcerárias e egressas do sistema carcerário de Joinville, mas expandiram o universo abordado pelo espetáculo para as muitas prisões femininas. Mulheres são poeticamente desenhadas em seus papéis sociais, conflitos internos e situações de coerção política.

A construção cênica não-dramática, calcada na performatização da atuação e nas relações polifônicas e dialógicas dos signos constituintes do espetáculo, procura oferecer uma pluralidade de significados em sua totalidade, compilando signos não ilustrativos e sim polissêmicos, incluindo a utilização de mídias diversas.

Recordando estas escolhas de linguagem, por mais que nós tivéssemos uma relação afetiva com a encenação original, concordamos que o direcionamento da composição cênica levava a uma relação subjetiva de construção de sentido, o que de fato pretendíamos naquele momento. Em celas procuramos abordar temáticas como maternidade, trabalho, vida doméstica, vícios, mídia e casamento a partir de

23 Texto escrito por mim em 2012, para inscrição da peça em festivais e editais de circulação. Material não publicado. 
questões apontadas nas narrativas das mulheres em situação de cárcere e egressas do cárcere às quais tivemos acesso, com a perspectiva de nossas experiências sendo mulheres e convivendo com outras mulheres. Para que essas vozes pudessem ser dialógicas e múltiplas, as dramaturgias da cena e do texto se pautavam na não-linearidade. Não havia uma fábula, nem um conflito principal à procura de um desfecho. Haviam tensões e texturas orquestradas em uma melodia de nuances que procurava construir possíveis particularidades nas vozes trazidas à cena enquanto discurso semântico, estético e político.

Contudo, nossos novos desejos de fala demandavam uma linguagem mais direta, que possibilitasse ao público conhecer, refletir e se conscientizar sobre as violências de gênero sofridas pelas mulheres, e pelas violências de gênero e de (in)justiça social sofridas pelas mulheres em situação de cárcere.

Nessa conversa instigada sobre as possíveis impressões de meu pai em relação à montagem original de celas, enquanto eu e Samira refletíamos sobre os novos caminhos a seguir, lembrei da perfopalestra como uma abordagem pedagógica possível para tentar alcançar este objetivo.

A primeira vez que ouvi o termo perfopalestra foi em 2016, em um evento promovido pelo Projeto de Extensão Mulheres em Cena, coordenado pela Profa. Dra. Maria Brígida de Miranda, do Departamento de Artes Cênicas do Centro de Artes da Universidade do Estado de Santa Catarina (UDESC). A perforpalestra foi apresentada pela Profa. Dra. Luciana Lyra (UERJ), e se intitulava Dramaturgia Feminina: o caldeirão de Afrodite. Nela, Luciana compunha uma cena ritualística, na qual abordava a mitologia de Afrotide para desenvolver relatos de pesquisa e exposições teóricas entremeadas por ações performáticas. Já em 2017, recebemos no Centro de Artes da UDESC a professora Dra. Lúcia Sander (UnB), a convite do Programa de Pós-Graduação em Teatro (PPGT). Em sua apresentação intitulada O que Shakespeare não contou, Lúcia abordou questões de gênero na obra do dramaturgo inglês transitando entre explanações históricas e teóricas, ações e representações de figuras que nos remetiam à obra e ao autor em questão. Nos anos seguintes, outras perfopalestras foram surgindo na UDESC, advindas principalmente de pesquisas e criações no campo do teatro feminista, relacionadas à disciplina Introdução ao Teatro Feminista ${ }^{24}$ (PPGT-UDESC) e às pesquisas desenvolvidas pela Profa. Dra. Maria Brígida de Miranda. Cito, como por exemplo: Bruxas, Santas, Loucas, Velhas, Meninas, Belas, Recatadas e do Lar, perfopalestra na qual Jussyane Emídio Rodrigues abordava a violência de gênero, intercalando relatos da santificação da menina Benigna no interior do Ceará - que faleceu vítima de uma tentativa de estupro -, e de imagens e discursos misóginos sobre a presidenta do Brasil Dilma Rousseff, veiculados durante o processo de golpe parlamentar que deflagrou o seu impeachment em 2016; e Nem uma a menos, de Stephanie Liz Polidoro e sua bufa Ternurinha, que abordavam questões de gênero e da agenda feminista analisando o contexto das mulheres em situação de rua.

Estas quatro perfopalestras citadas traziam algo em comum: a abordagem feminista em suas temáticas (a crítica à representação das mulheres na dramaturgia, a mitologia pautada na história de figuras femininas, as histórias de mulheres reais e as diversas violências de gênero sofridas, as condições específicas de mulheres às quais todos os direitos são negados). Todas estas questões refletem elementos tanto das agendas dos movimentos feministas, na luta por direitos e equidade de gênero, quanto do teatro feminista. Segundo a pesquisadora e professora Maria Brígida de Miranda

\begin{abstract}
Vale observar que práticas teatrais feministas se desenvolvem em momentos históricos e em culturas específicas; portanto deve ser pensado como um leque aberto a constantes construções e transformações. Historicamente é um termo que tem sido usado e definido por artistas e/ou pesquisadoras estadunidenses, inglesas e australianas desde
\end{abstract}

24 Disciplina ministrada em 2017, 2018 e 2019 pela Profa. Dra Maria Brígida de Miranda no PPGT da UDESC. Em 2019, tive o prazer de dividir a disciplina com a professora Brígida, devido a seu afastamento para usufruto de licença-prêmio. 
a década de 1960. Adoto a definição da pesquisadora britânica Lizbeth Goodman, que em seu livro Contemporary Feminist Theatre: To each her own (1993), ao fazer um apanhado das práticas teatrais feministas na Grã-Bretanha a partir de 1968, propõe que o teatro feminista precisa de uma definição flexível. Para Goodman o teatro feminista é tanto uma forma de arte como uma plataforma, uma forma de entretenimento e um fórum de comunicação de ideias políticas feministas. (MIRANDA, 2018, p. 237).

Assim, reconheço nestas perfopalestras ${ }^{25}$ epistemologias feministas e diálogo direto com o teatro feminista em sua multiplicidade estética, no intuito comum de contar as histórias das mulheres sobre as perspectivas das mulheres, problematizando questões de gênero como forma de ação política na arte.

Eu e Samira também partilhávamos destes desejos. Então, desmontamos a peça celas, recriando a relação com o espaço e o público, cenário, figurinos, adereços e a dramaturgia. Abrimos mão de algumas cenas, mantivemos outras e criamos novas, transformando a peça em uma desmontagem teatral e perfopalestra, abrindo espaço para que as vozes das mulheres em situação de cárcere pudessem estar mais presentes, em cartas, áudios, e em análises sobre a condição das mulheres brasileiras nas prisões.

Criamos um prólogo para este trabalho, com o intuito de gerar um incômodo nas pessoas, antes da entrada no espaço cênico. Eu, Cleiton e Jackson ${ }^{26}$,

25 Catalão (2017) procura estabelecer uma genealogia para a palestra-performance, partindo da premissa que esta visa apropriar o espaço crítico como espaço cênico (artístico). O pesquisador aponta para ações de artistas visuais, músicos, escritores e performers, que desde o século XIX criam experiências que podem ser compreendidas no âmbito da palestra-performance. Todavia, neste presente artigo eu procuro apontar como o teatro feminista, principalmente em experiências que chegam até a UDESC e se multiplicam em outras ações vinculadas à instituição, apropria-se da linguagem como uma estratégia de criação, inclusive renominando o termo.

26 Tivemos a participação de meus orientandos de iniciação científica neste prólogo, Guilherme Luiz Porte e Caê Beck, na apresentação realizada na Mostra Rosa Teatral, na UDESC-CEART em outubro de 2019, substituindo Cleiton e Jackson que não puderam estar presentes. vestidos de preto, assim como os agentes carcerários que conhecemos no PRJ, recebíamos o público no lado de fora do espaço cênico, formando filas, distribuindo crachás de visitantes e recolhendo celulares. Esta ação gerava certo desconforto, o que de fato era nossa intenção, pois nossas experiências na entrada do PRJ para as aulas de teatro sempre foram de longas esperas, revistas em bolsas, passagem por scanner de objetos e corpo, mais espera, gerando uma sensação de invasão e controle muito grande.

O livro Encarceramento em massa, de Juliana Borges (2019) ofereceu dados estatísticos e importantes reflexões com perspectiva de gênero sobre legislações, prisões e o encarceramento de mulheres no Brasil, utilizadas tanto em jogos de cena com a plateia quanto em momentos em que as narrativas da atriz e da diretora traziam um discurso crítico.

Tendo em vista a crescente apologia à violência de gênero desde o início do processo de golpe parlamentar contra a presidenta Dilma Rousseff até a eleição do atual presidente da República, além das declarações desumanas sobre pessoas em situação de cárcere deste, em um momento entre cenas de celas trouxemos ao público cartazes com frases do atual presidente, que representam sua misoginia e o ataque aos direitos humanos. Apesar das frases não terem a identificação de quem as proferiu, é muito difícil não identificar o interlocutor, e não se impactar com a constatação de que aquele que deveria ser o representante maior da nação e defensor dos direitos das cidadãs e cidadãos é, na verdade, um grande opressor dos grupos já historicamente oprimidos e desprivilegiados socialmente. Mulheres, negras/os, LGBTs, indígenas, pessoas em situação de cárcere, pobres, enfim, toda a gama de pessoas periféricas que deveriam ter seus direitos garantidos de acordo com a Constituição Federal de 1988 vêm tendo seus direitos perseguidos e tolhidos veementemente. Estas violências verbais se refletem em violências patrimoniais, psicológicas e físicas, pela sensação de uma "autorização" do representante maior da nação ao desrespeito e agressão a estas pessoas. Por compreender este trabalho como um trabalho em 
processo, depois de algumas apresentações realizadas alteramos esta ação por uma questão técnica: percebemos que as folhas nas mãos das pessoas geravam certo incômodo, por elas não saberem o que fazer com os papéis. Assim, na apresentação ocorrida em outubro de 2020 na III Mostra Rosa Teatral da UDESC ${ }^{27}$, nesta entre cena apenas Samira segurou uma folha com uma frase proferida pelo atual presidente da República, que sintetiza, de algum modo, a gama de ofensas aos direitos humanos, e especificamente às pessoas em situação de cárcere, que o mesmo profere reiteradamente: "Preso não deve ter direito nenhum, não é mais cidadão. O sentido da cadeia não é ressocializar, mas tirar o marginal da sociedade"28. Percebemos que mesmo expondo apenas esta frase ao público, juntamente com a música e a dramaturgia da atriz neste contexto, o impacto desejado podia ser gerado: é uma frase muito cruel, que destoa do contexto de um país democrático de direito. Mesmo o interlocutor podendo não ser identificado por algumas pessoas, a tensão gerada nesta ação em relação à cena anterior e às nossas falas iniciais explicitava a crítica à necropolítica ${ }^{29}$ aplicada pelo Estado e replicada muitas vezes pela sociedade às pessoas em situação de cárcere.

$\mathrm{Na}$ última cena/quadro/momento de celas $e$ elas, a atriz lê uma carta escrita por uma das alunas reeducandas da oficina de teatro realizada no

27 A Mostra Rosa Teatral é uma ação do Programa de Extensão Mulheres em Cena, coordenado pela Profa. Dra. Maria Brígida de Miranda, do Departamento de Artes Cênicas do Centro de Artes da Universidade do Estado de Santa Catarina (UDESC). Em $2019 \mathrm{fiz}$ a co-coordenação da mostra, devido ao afastamento da professora Brígida para usufruto de licença-prêmio.

28 Frase proferida na entrevista concedida por Jair Bolsonaro ao Canal Livre em 20/11/2017. Frase retirada da reportagem da Folha de São Paulo sobre a entrevista. Disponível em: https://www1.folha.uol.com.br/poder/2017/11/1936715-se-nao-houver-fraude-estarei-no-2-turno-diz-bolsonaro.shtml Acesso em maio de 2020.

29 Conceito desenvolvido pelo filósofo camaronês Achille Mbembe (2018) para criticar políticas e ações de Estado que, baseadas no discurso da segurança, segregam e exterminam grupos sociais historicamente oprimidos e marginalizados.
PRJ em 2019, em um exercício de aula. Na carta, após um relato emocionante sobre sua infância, adolescência, casamento, maternidade, separação (resultado do abandono da família após a prisão - realidade de muitas mulheres neste contexto), e reencontro do amor na prisão, além do relato das condições complexas do cárcere, ela faz uma crítica contundente ao sistema prisional brasileiro, expressando toda a sua consciência política e lucidez em relação às violências cometidas pelo Estado:

Fico pensando se as autoridades sabem que tudo é uma barbárie, uma catástrofe e que isto sai muito caro, eu me pergunto: Porque eles prendem miseráveis? Vejo casos com os quais enlouqueço! Pois governadores, parlamentares são presos por bilhões e são em seguida, beneficiados enquanto eu com 03 gramas de craque fui sentenciada há sete anos e nove meses. Estou presa há três anos e tenho que pagar quatro anos e oito meses para alcançar algum benefício, por esses motivos eu me pergunto: Por que não refletem sobre os motivos das mulheres se envolverem com o crime? Por que este aumento brutal de mulheres presas, sendo que a maiorias fez pelos filhos, pelo marido, por amor? Por que os Juízes pouco aplicam as penas alternativas e muito menos as medidas cautelares que não a prisão? Por que não se pensa que a prisão rompe as relações familiares e traz consequências danosas para os filhos das presas? Por que o indulto natalino nunca beneficia as mulheres?

O quê dizer depois de ouvir estas palavras que retratam duramente as injustiças do sistema judiciário e penal? Que desenham em nossas mentes a violência institucional cometida diariamente contra essas muIheres? Nos resta ouvir, refletir e atuar vigorosamente na conscientização da sociedade pelo fim das prisões.

Angela Davis $(2009,2018)$ nos mobiliza através de seu ativismo social, político e acadêmico a pensar sobre a relação direta entre sistema prisional e escravidão, que revela não só a falência do discurso de ressocialização promovido por este sistema, mas também sua íntima ligação com o capitalismo e a exploração dos corpos. Apesar da autora prospectar suas críticas ao sistema prisional 
estadunidense, podemos fazer um paralelo com a realidade brasileira. A lei n.11.343 de 2006, conhecida como Lei antidrogas, promoveu um aumento de mais de $700 \%$ da população prisional entre os anos de 2006 e 2016, e de mais de $560 \%$ da população prisional feminina, sendo estas pessoas, em sua maioria, negras ${ }^{30}$ (BORGES, 2019). Juliana Borges (2019) aponta para dados alarmantes, como o fato de $40 \%$ das pessoas encarceradas estarem em prisão provisória, sem julgamento realizado. Como contudentemente expôs a carta de nossa aluna do PRJ, “(...) Por que os Juízes pouco aplicam as penas alternativas e muito menos as medidas cautelares que não a prisão?". Nosso sistema judiciário, que vergonhosamente ocupa o terceiro lugar no mundo no ranking de pessoas encarceradas ${ }^{31}$, é um sistema racista, classista, misógino e escravocrata, que pratica a necropolítica como estratégia neoliberal de punitivismo e defesa da propriedade privada em detrimento do combate das vulnerabilidades sociais.

\section{Lugares de fala e lugares de escuta:} um exercício

Durante os 11 anos de pesquisa, montagem e desmontagem de celas e Celas e Elas procuramos constantemente realizar o exercício ético da escuta e da fala. Antes do conceito de lugar de fala ser disseminado com a obra de Djamilla Ribeiro (2017), eu e Samira já nos movíamos nestas reflexões em nossas conversas e ensaios sobre as linhas tênues do teatro, que formam a trama de representações, narrativas, histórias e ações da cena. Pensar em nosso espaço social privilegiado, de "mulheres brancas, de classe média, cisgênero, heterossexuais, que não estão confinadas em uma cela superlotada", como expomos na dramaturgia de celas e elas, foi

30 No PRJ a maioria das alunas que frequentaram o curso de teatro eram brancas. Tivemos, dentre as 34 alunas que passaram pela oficina, apenas 02 alunas negras.

31 Disponível em: http://www.ihu.unisinos.br/159-noticias/ entrevistas/575856-paradigma-do-punitivismo-coloca-o-brasil-em-terceiro-lugar-no-ranking-mundial-do-encarceramento-entrevista-especial-com-juliana-borges. Acesso em abr. de 2020. um dos exercícios que compuseram o percurso de treinamento e o processo criativo destes trabalhos.

Como a própria Djamilla Ribeiro pontua,

Um dos equívocos mais recorrentes que vemos acontecer é a confusão entre lugar de fala e representatividade. Uma travesti negra pode não se sentir representada por um homem branco cis, mas esse homem branco cis pode teorizar sobre a realidade das pessoas trans e travestis a partir do lugar que ele ocupa. Acreditamos que não pode haver essa desresponsabilização do sujeito do poder. A travesti negra fala a partir de sua localização social, assim como o homem branco cis. Se existem poucas travestis negras em espaços de privilégio, é legítimo que exista uma luta para que elas, de fato, possam ter escolhas numa sociedade que as confina em determinado lugar, logo, é justa a luta por representação, apesar de seus limites. Porém, falar a partir de lugares é também romper com essa lógica de que somente os subalternos falem de suas localizações, fazendo com que aqueles inseridos na norma hegemônica sequer se pensem. Em outras palavras, é preciso, cada vez mais, que homens brancos cis estudem branquitude, cisgeneridade, masculinos. Como disse Rosane Borges, para a matéria O que é lugar de fala e como ele é aplicado no debate público, pensar lugar de fala é uma postura ética, pois "saber o lugar de onde falamos é fundamental para pensarmos as hierarquias, as questões de desigualdade, pobreza, racismo e sexismo". (RIBEIRO, 2017, p. 86).

Em diálogo com estes pressupostos, procuramos na primeira versão do trabalho, celas, trazer na encenação ações e narrativas que não remetessem diretamente ao ambiente da prisão, trabaIhando com a prisão como metáfora das opressões sociais sofridas pelas mulheres como nós, nossas mães, irmãs, vizinhas, esperando que este espaço pudesse criar fissuras de crítica na ação-ficção das cenas a partir daquilo que trazíamos como experiência de ser mulher. Já em Celas e Elas, a necessidade de enfrentar diretamente o contexto do cárcere nos levou à desmontagem e à perfopalestra como linguagens possíveis para implicarmos nossas vozes de artistas mulheres nas narrativas ficcionais 
do celas original, entrelaçando nossas visões de mundo, experiências e lugares de fala às das muIheres que ocupam as prisões do PRJ e do Brasil.

Neste processo, em busca de ocupar conscientemente nossos lugares de fala, procuramos também nossos lugares de escuta. Márcia Tiburi (2018, p. 56) afirma que o lugar de escuta "É o desejo político que surge no lugar de fala", e que "a escuta é um elemento prático no processo político que precisa ser experimentado com urgência, sobretudo pelos sujeitos que detém o privilégio da fala". Se faz necessário compreender aqui a "fala" como ação, em sua condição performativa, ou seja como um espaço de poder social que nos permite estar e agir em um determinado contexto.

Já Jota Mombaça, ao refletir sobre os espaços acadêmicos na construção de epistemologias hegemônicas, demanda pela escuta das vozes subalternas como um exercício não só de representatividade, mas de descondicionamento da escuta dominante:

[...] é possível dizer que, as falas subalternas, para a escuta dominante, vibram como os infra e ultrassons para a escuta humana, fora do campo de audibilidade. Nesse sentido, interrogar o marco do que pode ser ouvido nos termos da cultura euro-americana, colonial, heterocentrada e cisnormativa dominante configura um gesto político-teórico no sentido de uma descolonização, um remapeamento da escuta que leva em consideração o ruído e as linhas-de-fuga que ele fissura na harmonia sobreposta. (MOMBAÇA, 2015, n. p.).

A provocação que Jota Mombaça nos faz exigir reconhecer a impossibilidade da universalidade e da neutralidade: todas nós estamos imbuídas de nossas visões de mundo e de nossos lugares de fala e escuta, que nos remetem a privilégios ou a exclusões históricas; à naturalização e reprodução das ações de opressão ou ao questionamento crítico de nossas ações.

Assim, não há lugar de fala sem escuta, a si e ao seu entorno. O descondicionamento da escuta é uma ação física que envolve o desejo, a intenção e o conhecimento crítico dos processos históricos. Reconhecer-mo-nos como seres culturais, envoltos em diversos agenciamentos que incluem a escuta de vozes, palavras e corpos, e o julgamento daquilo que ouvimos, pode nos ajudar a desenvolver uma consciência mais crítica sobre nossos lugares de fala e nossos papéis políticos e sociais, na arte e na vida cotidiana. E foi este o exercício que procuramos realizar em celas e Celas e Elas, conscientes que não podemos "dar voz" a ninguém, mas sim questionar e nos somar às lutas a partir do espaço social e artístico que ocupamos.

\section{Vozes que ecoam}

$\mathrm{O}$ ativismo artístico dos projetos e trabalhos abordados neste artigo se projetam neste texto como um ativismo acadêmico, com o intuito de refletir politicamente sobre a arte que fazemos.

Procurei aqui contextualizar o processo de pesquisa, criação, montagem e desmontagem da peça celas em Celas e Elas, sintetizando reflexões e procedimentos dos percursos traçados por um trabalho que completa onze anos em 2021, desde a concepção do primeiro projeto até o momento em que reviso a escrita deste texto.

Relatei o contato com as mulheres em situação de cárcere desde as pesquisas inicialmente cedidas para a montagem de celas até o desenvolvimento de um curso de teatro com mulheres em situação de cárcere do PRJ, procurando refletir como estas experiências nos afetaram e moveram na criação de duas peças de teatro: a primeira celas, um espetáculo solo performático multimídia, e a segunda Celas e Elas, uma desmontagem teatral e perfopalestra.

Os lugares de fala e escuta que procuramos exercitar como mulheres artistas nestes processos também foram debatidos conceitualmente, com o intuito de oferecer ferramentas teóricas para pensarmos ações políticas necessárias no campo das artes cênicas da atualidade.

A desmontagem teatral celas e elas seguiu em 2020 com exibições de filmagens da peça e rodas de conversa online, devido ao distanciamento social 
demandado pela pandemia mundial de covid-1932. Pelo mesmo motivo, Celas e Elas também teve que adiar apresentações em espaços culturais e presídios de cidades de quatro diferentes regiões do Estado de Santa Catarina, viabilizadas pelo Prêmio Elisabete Anderle de Estímulo à Cultura ${ }^{33}$ em 2019.

Finalizo os relatos e reflexões deste texto compartilhando um pedido contido na carta que a aluna do PRJ nos cedeu para leitura pública em Celas e Elas. Procuremos, então, exercitar nossas escutas nos espaços de privilégio que porventura ocupamos, não nos furtando de nossa responsabilidade nas lutas sociais. Para pensar uma sociedade mais justa precisamos ser feministas, antirracistas, anticapitalistas, anticapacitistas, abolicionistas e antipunitivistas. Assim, quem sabe, possamos finalmente escutar e olhar para as pessoas, e não apenas para números:

Quero uma coisa, que olhem para mim! Para mim e para todas as mulheres que estão na prisão... na minha situação, 'querer não é poder', mas o que eu sinto no meu coração e falo em nome de todas as presas do sistema prisional de Joinville é que jamais devemos esquecer que existe um Deus, e onde há esperança... essa permanecerá para sempre.

BORGES, Juliana. Encarceramento em massa. São Paulo: Sueli Carneiro; Pólen, 2019.

CABALLERO, Ileana Diéguez. Des/tecer, des/montar, desvelar. In: Desmontagens: processos de pesquisa e criação nas artes da cena. Rio de Janeiro: 7 Letras, p. 10-19, 2018.

32 Maiores informações em: https://covid.saude.gov.br Acesso em mai. de 2020.

33 Projeto "Celas e Elas - circuito de apresentações e exposições". Proponente: Samira Sinara Souza. Promoção: Fundação Catarinense de Cultura, 2019. As apresentações iniciariam em abril de 2020 , mas foram adiadas para quando o contexto sanitário e de saúde permitir suas realizações presenciais.
CATALÃO, Marco. Uma genealogia para a palestra-performance. Urdimento, v. 1, n. 28, 2017.

DAVIS, Angela Y. A democracia da abolição: para além do império, das prisões e da tortura. Trad. Arthur Neves Teixeira. Rio de Janeiro, Difel, 2009.

. Estarão as prisões obsoletas? Trad. Marina Vargas. 1a. ed. Rio de janeiro: Difel, 2018.

JACOBS, Daiane Dordete Seckert; SOUZA, Samira Sinara. Sobre cartas, celas, elas e professoras-em-processo. Urdimento - Revista de Estudos em Artes Cênicas. v. 3, n. 39, 2020.

MBEMBE, Achille. Necropolítica: biopoder, soberania, estado de exceção, política da morte. Tradução Renata Santini. 3a. Ed. São Paulo: n. 1 Edições, 2018.

MIRANDA, Maria Brígida de.Colcha de Memórias: epistemologias feministas nos estudos das artes da cena. Urdimento: Revista de Estudos em Artes Cênicas. v. 3, n. 33, 2018.

MOMBAÇA, Jota. Pode um cú mestiço falar? Site Medium, 06 jan. de 2015. Disponível em: https://medium.com/@jotamombaca/pode-um-cu-mestico-falar-e915ed9c61ee. Acesso em abri. de 2020.

RIBEIRO, Djamilla. O que é lugar de fala? Belo Horizonte, MG: Letramento: Justificando, 2017.

TIBURI, Márcia. Feminismo em comum: para todas, todes e todos. 8a. Ed. Rio de Janeiro: Rosa dos Tempos, 2018.

Recebido: 09/11/2020

Aceito: 29/03/2021

Aprovado para publicação: 13/04/2021 
Este é um artigo de acesso aberto distribuído sob os termos de uma Licença Crea- tive Commons Atribuição 4.0 Internacional. Disponível em: <http://creativecommons.org/licenses/by/4.0>.

This is an open-access article distributed under the terms of the Creative Commons Attribution License 4.0 International. Available at: <http://creativecommons.org/licenses/by/4.0>.

Ce texte en libre accès est placé sous licence Creative Commons Attribution 4.0 International. Disponible sur: <http://creativecommons.org/licenses/by/4.0>. 